\title{
Applications of Electromagnetic Field to Continuous Casting Process of Steel
}

ISSN: 2576-8840

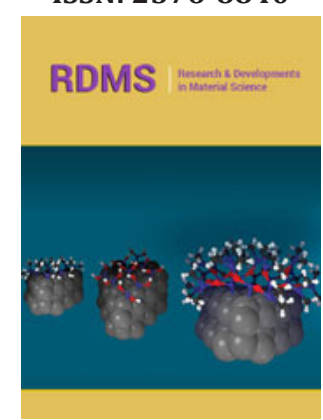

*Corresponding author: Hiroshi Harada, Graduate School of Engineering, Nagoya University, Furo-cho, Chikusa-ku, Nagoya, Japan

Submission: 眥 September 07, 2021

Published: 制September 15, 2021

Volume 15 - Issue 4

How to cite this article: Hiroshi Harada. Applications of Electromagnetic Field to Continuous Casting Process of Steel. Res Dev Material Sci. 15(4). RDMS.000870. 2021. DOI: 10.31031/RDMS.2021.15.000870

Copyright@ Hiroshi Harada. This article is distributed under the terms of the Creative Commons Attribution 4.0 International License, which permits unrestricted use and redistribution provided that the original author and source are credited.

\section{Hiroshi Harada*}

Graduate School of Engineering, Nagoya University, Japan

\section{Introduction}

CC (Continuous Casting) process is regarded as a landmark technology, which had revolutionized steel production along with LD converter process. Toward SDGs, not only the technology which enables higher quality steel products with higher productivity but also the one which enables new steel products with distinctive features and quality, are of demand. Electromagnetic force has an advantage, that can control the fluid velocity field and temperature field without contact with molten metal [1]. Therefore, numerous technologies that apply electromagnetic field to the CC process have been developed and contributed to the marked technological progress of continuous casting process, as shown in Table 1. In this paper, among the main functions of electromagnetic field, the applied technologies to CC mold have been overviewed and new application of electromagnetic field has been proposed with consideration of magnetic property of steel.

Table 1: Main functions of electromagnetic field and application examples.

\begin{tabular}{|c|c|c|c|}
\hline Principle & Function & Field & Example \\
\hline \multirow{5}{*}{ Lorentz Force } & Flow Promotion & $\mathrm{AC}$ & Electromagnetic Stirring, Electromagnetic Pump \\
\hline & Flow Suppression & $\mathrm{DC} / \mathrm{AC}$ & Electromagnetic Brake, Wave Suppression \\
\hline & Levitation & $\mathrm{AC}$ & $\begin{array}{c}\text { Electromagnetic Casting, Cold Crucible, } \\
\text { Levitation }\end{array}$ \\
\hline & $\begin{array}{l}\text { Solidification Structure } \\
\text { Control }\end{array}$ & $\mathrm{AC}$ & $\begin{array}{l}\text { Electromagnetic Stirring, Pulse Current } \\
\text { Imposition }\end{array}$ \\
\hline & Separation & $\mathrm{DC} / \mathrm{AC}$ & Nonmetallic Inclusion Removal \\
\hline \multirow{2}{*}{ Joule Heating } & \multirow{2}{*}{ Heating } & AC & Induction Heating \\
\hline & & DC & Plasma Heating \\
\hline Lenz's Law & Detection & AC & Level Sensor, Veocimetry, Slag Flowout Detection \\
\hline
\end{tabular}

(AC: Alternative Current, DC: Direct Current)

\section{Control of molten steel flow with electromagnetic field}

The application of EMS (Electro-Magnetic Stirring) to CC process has comparatively long history and first trial of EMS went back to 1960's [2]. Strand EMS opened the door of real application of EMS to CC machine at the late of 1970's [3,4]. The objective of Strand EMS is to acquire the high equiaxed zone ratio for the purpose of suppression of the center segregation. After that, in-mold EMS had been developed to improve the surface quality of slab by suppression of entrapment of nonmetallic inclusions and Ar bubbles to solidified shell [5].

In 1980's, in order to attain the high productivity of CC process, EMBr (Electro-Magnetic Brake) had been developed to stabilize the molten steel flow in CC mold. The first type of EMBr 
is local magnetic field that a pair of DC magnets have been installed at the neighborhood of the SEN (Submerged Entry Nozzle) port and the imposed field brake the discharged flow from SEN directly [6]. The second type of EMBr is level magnetic field that uniform magnetic field in the width direction of mold, develops plug- like flow below magnetic field area $[7,8]$. One kind of second type of $\mathrm{EMBr}$ is FC mold (Flow-Control mold) that the imposition of a pair of level magnetic field at the upper part of CC mold, simultaneously stabilize the meniscus flow and descending flow along the narrow face of mold [9]. At present, the combination of EMS and EMBr have been also developed [10].

Takeuchi et al. [11] developed the continuous casting process for clad steel slabs by suppressing the mixing of molten steels in the strand with electromagnetic brake. In this process, two molten steels of different composition are simultaneously supplied through two submerged entry nozzles into the upper and lower pools in the CC mold to form the outer and inner layers, respectively. The casting principle had been verified by the pilot scale continuous casting experiments and numerical analysis.

Steel transforms magnetically from ferromagnetic to paramagnetic at Curie point and then to nonmagnetic at higher temperature. Noticing that the narrow face of slab has been cooled to around the Curie point at the beneath of CC mold and the deviated flow in CC strand leads to the difference of solidified shell growth, electromagnetic sensor measuring the slab surface temperature have been studied [12]. Plant tests by installing the sensors under the respective narrow face mold, have been performed to clarify that the proposed sensor could measure surface temperature of slab under severe conditions and detect the deviated flow in CC strand by using the estimated temperature difference.

\section{Conclusion}

This paper reviews the history of application of electromagnetic field to CC process. Various actuators have been developed to contribute to increase the productivity and improve the quality. As mentioned previously, the electromagnetic sensor can visualize the solidification phenomena in CC mold without any contacts. Further developments of sensors and actuators can control the solidification phenomena in CC process in the advanced way. Moreover, the combination of numerical calculation and information technologies widen the potential of CC process toward Sustainable Development Goals.

\section{References}

1. Asai S (1989) A birth of electromagnetic metallurgy and it's recent trends. $129^{\text {th }}, 130^{\text {th }}$ Nishiyama Memorial Lecture, ISIJ, Tokyo, Japan, p. 4.

2. Ayata K (1989) Application of transferring electromagnetism. $129^{\text {th }}, 130^{\text {th }}$ Nishiyama Memorial Lecture, ISIJ, Tokyo, Japan, p. 103.

3. Marr HS (1979) Electromagnetic stirring: Stepping stone to improved continuous cast products. Iron and Steel International, p. 29.

4. Ujiie Y, Maede H, Itoh K, Ogibayashi S, Seki H, et al. (1981) Improving solidification structure of continuously cast steel by electromagnetic stirring. Tetsu-to-Hagane 67: 1297.

5. Takeuchi E, Fujii H, Ohashi T, Tanno H, Takao S, et al. (1983) Continuous casting of pseudo-rimmed steel with electromagnetic stirring in the mold. Tetsu-to-Hagane 69(14): 1615-1622.

6. Nagai J, Suzuki K, Kojima S, Kollberg S (1984) Steel flow control in a highspeed continuous slab caster using an electromagnetic brake. Iron Steel Engineer 61(41).

7. Ishii T, Konno N, Okazaki T, Uehara T, Takeuchi E, et al. (1996) The electromagnetic brake technique with level DC magnetic field-1 (development of high-quality stabilization technology of the continuous caster -8). CAMP-ISIJ 9: 206.

8. Harada H, Takeuchi E, Zeze M, Ishii T (2000) New sequential casting of different grade of steel with level DC magnetic field. Tetsu-To-Hagane 86(4): 278-284.

9. Idogawa S, Tozawa K, Takeuchi S, Sorimachi K, Sugisawa M et al. (1996) Control of molten steel flow in a continuous casting mold by two static magnetic fields covering whole width. CAMP-ISIJ 9: 618.

10. Thomas BG, Cho SM (2018) Overview of electromagnetic forces to control flow during continuous casting of steel. Proceedings of $9^{\text {th }}$ International Symposium on Electromagnetic Processing of Materials (EPM2018), Awaji-Island, Japan.

11. Takeuchi E, Zeze M, Tanaka H, Harada H, Mizoguchi S (1997) Novel continuous casting process for clad steel slabs with level DC magnetic field. Ironmaking and Steelmaking 24: 257.

12. Harada H, Nagashima M, Konno T, Yamana M, Toh T (2020) Detection of unbalanced flow in cc strand by using electromagnetic sensor under the principle of magnetic transformation of steel. Tetsu-To-Hagane 106: 187.

For possible submissions Click below: 